\title{
ESSENTIAL OILS, A POSSIBLE SOLUTION TO OVERCOME ANTIMICROBIAL RESISTANCE CRISIS
}

\author{
Adrian-Vasile Craciun ${ }^{1,2}$, Daniela Chiru ${ }^{1,2}$, Otilia Marginean ${ }^{1,2}$ \\ 1 "Victor Babes" University of Medicine and Pharmacy, Department of Pediatrics, \\ First Pediatric Clinic, Timisoara, Romania \\ 2 “Louis Turcanu” Emergency Hospital for Children Timisoara, Romania
}

\begin{abstract}
Having emerged as an ideal solution against pathogenic microorganisms, antimicrobial medication seems to have lost the battle today. The ability of the living world to survive and adapt exceeds the synthetic products power of action, leading us today to a real crisis of microbial resistance to antibiotics.

An unexpected solution may come also from the bosom of nature, by reconsidering the role and place of the essential oils as antimicrobial combat weapons. Defensive mechanisms created by nature, the essential oils demonstrate extraordinary antibacterial, antiviral and antifungal activity. They also help the synthetic antibiotics in their battle. Among the essential oils and the antibiotics, often intervene synergistic or additive interactions. The essential oils favor the antibiotics to penetrate through the cell wall and to extend their action spectrum.

Undoubtedly, essential oils can be of crucial help in the current medical practice, through their complex antibacterial, antiviral and antifungal action.
\end{abstract}

Keywords: essential oils, antimicrobial, antibiotic resistance, synergism, additive effects

\section{INTRODUCTION}

Already hundred years passed, since Paul Ehrlich introduced the term chemotherapy, meaning a treatment based on chemical substances. If before 1913, the medicine used mainly natural products under various forms (tee sorts, decocts, tinctures, powders, essential oils, etc.) containing hundreds or thousands of chemical substances, starting with Paul Ehrlich came a change in the therapy perspective, by introduction of the mono-compound drugs. The term "phyto-complex" was forgotten or ignored, whilst new chemical synthesis substances were more and more elaborated, among which a main place was reserved to the antimicrobial drugs.

The trust of the medical world in the new synthesis antibiotics was so high, that in 1964, Dr. Cockburn M.D. declared that ,...we can look forward with confidence to a considerable degree of freedom from infectious diseases at a time not too far in the future. Indeed...it seems reasonable to an- ticipate that within some measurable time... all the major infections will have disappeared...." $(1,2)$.

50 years after this statement (2014), Professor Gian Maria Rossolini Ph.D., coordinator of the Laboratory of Microbial Physiology and Biotechnology, Department of Molecular Biology from Siena writes: "Antibiotics tend to lose their efficacy over time due to the emergence and dissemination of resistance among bacterial pathogens. Strains with resistance to multiple antibiotic classes have emerged among major Gram-positive and Gramnegative species including Staphylococcus aureus, Enterococcus spp., Pseudomonas aeruginosa, Acinetobacter spp. Enterobacteriaceae, and Neisseria gonorrhoeae. With some Gram-negatives, resistance may involve most or even all the available antimicrobial options, resulting in extremely drugresistant or totally drug-resistant phenotypes. This so-called 'antibiotic resistance crisis' has been compounded by the lagging in antibiotic discovery and development programs occurred in recent

Corresponding author:

Adrian Craciun, "Louis Turcanu” Emergency Hospital for Children Timisoara, Romania

E-mail: craciun.adrian@umft.ro 
years, and is jeopardizing the essential role played by antibiotics in current medical practices." (3)

In the same context, the American Center for Disease Control and Prevention publishes on their official site: "Carbapenem-resistant Enterobacteriaceae $(C R E)$... are a family of germs that are difficult to treat because they have high levels of resistance to antibiotics. Klebsiella species and Escherichia coli (E. coli) are examples of Enterobacteriaceae, a normal part of the human gut bacteria that can become carbapenem-resistant... Some CRE bacteria have become resistant to most available antibiotics. Infections with these germs are very difficult to treat, and can be deadly-one report cites they can contribute to death in up to $50 \%$ of patients who become infected." (4)

Alarm signs come also from the World Health Organization, which states in a report from 2012 the following, regarding the resistance to antibiotics: "Antimicrobial resistance (AMR) threatens the effective prevention and treatment of an ever-increasing range of infections caused by bacteria, parasites, viruses and fungi. It is an increasingly serious threat to global public health that requires action across all government sectors and society. AMR is present in all parts of the world. New resistance mechanisms emerge and spread globally." (5)

The Nature Magazine publishes May 2014 an article by Professor Mark Woolhouse, Ph.D., where the professor declares that "The time has come to stop re-stating the problems of antimicrobial resistance and start taking action. We need independent, international leadership on this issue before the massive health gains that have been made since Alexander Fleming's discovery of penicillin are lost forever." (6)

The arrogance of the new antibiotic drugs seems to get stuck in the infinite resources of nature, to adapt to aggression. The most alarming signals in this sense, coming as well from the World Health Organization, as well as from other leaders in the contemporary antimicrobial research, urge for the finding of solutions. The return towards nature and to the infinite possibilities which nature offers us, may be one of these solutions.

\section{ESSENTIAL OILS IN THE ANTIMICROBIAL BATTLE}

The essential oils, also called volatile or aromatic oils (UE) represent secondary products of the plants' metabolism. Accumulated in vacuoles, collecting bags, glandular hairs or secretor channels, they provide the antimicrobial defense of the plant (antibacterial, antiviral, antifungal, antiparasitary). Besides their protective role, the essential oils act for attracting some insects, animals or birds, thus having a determinant role in the reproduction, or as healing substances of the „wounds”, or as protective membrane, against the loss of water. Several studies show also a major antioxidant role of the volatile oils (7). The constituents of the volatile oils are also energy vectors, by the conceding of electrons or protons. The composition of the essential oils is very complex, they can contain up to 5,0007,000 various chemical compounds. Among these, a major importance have the alcohols (mono- and sesquiterpenic), as well as the aromatic compounds.

The first proofs on the use of essential oils as therapy date from the year 5,000 B.C., in Pakistani, where the archeological researches found a burnt soil alembic, used to the obtaining of these oils. An inscription discovered in Mesopotamia, over 4,000 years old, mentions the use of essential oils, as disinfectants in the eradication of epidemics. Brahman prayers destined to the aromatic plants have been formulated 1,500-2,000 years B.C. (8).

By their complex composition, the volatile oils manifest several properties, which make them extremely useful in the complementary therapy, as for example: antimicrobial (antibacterial, antiviral, antifungal), antiparasitary, cicatrizing, antioxidant, analgesic, antispastic, antilithiasic, antihistaminic, anti-inflammatory, mucolytic and expectorant, immunostimulatory, carminative, stomachic, sedative, antidepressive or reviving tonic. Their action is not only due to their chemical compounds, as also to the electrical charge and especially to the informational compound, transmitted by the electromagnetic waves, with proven action on the neuro-endocrine receptors (8).

The antimicrobial properties of the essential oils are nowadays studied intensively and many scientists believe that their association with the already existent antibiotics may represent a solution to the crisis of the bacterial resistance, which we are confronted with at present $(2,9,10,11)$.

An advantage of the essential oils is given by their complex chemical composition. Although, their antimicrobial properties are mainly determined by the dominant phenolic (or alcoholic) structure, in the composition of the oil are beside this hundreds of other chemical compounds, whose role is to modulate the effect of the main ingredient. Therefore is the antimicrobial activity of the oil as a complex of substances net superior, in comparison to the antimicrobial effect of each ingredient separately (12). Therefore, we always speak in the 
traditional medicine about a phyto-complex and not about individual chemical compounds. The ability of the essential oils, to avoid the installing of the microbial resistance depends also on the complex character of the chemical composition. A micro-organism may develop a resistance mechanism to one, two, or maybe to three active substances, but never to hundreds of various molecules, which assault it from all directions. Although there are at present just a few studies on this matter, a good example may be offered by the use of the Tea tree oil in Australia since 1920, until now not being noticed the installing of any microbial resistance to it. (13)

\section{Antibacterial activity of the essential oils}

A contemporary study direction in medicine represents the analysis of the combination between the essential oils and the antibiotics, in the antibacterial battle. This association has been proven to be beneficial most of the time, enhancing in fact the antibacterial effect of the complex, in comparison to the individual administration of the two compounds (synergic effect) (10). Here some examples of synergic effect: the association of Oregano Oil with the fluoroquinolones and with Lincomycin against E. Coli (14), Rosmarinus officinalis and Ciprofloxacin against the Klebsiella pneumonia (15), Zataria multiflora and Vancomycin against the Staphylococcus aureus (including the MRSA strains) (16), Citrus limon or Cinnamonum zeylanicum and Amikacin, against the Acinetobacter spp. (17), Aniba rosaeodora or Pelagronium graveolens and Norfloxacin against numerous bacterial species, as for example Bacillus cereus, Bacillus subtilis, S. Aureus, E. coli, Acinetobacter baumannii, Seratia marcescens, Yersinia enterocolitica (18).

Wessler and colleagues have emphasized in 2005 over 20 aromatic oils with an action against Helicobacter pylori (19) and Inouye and colleagues have proven the antibacterial effect of Thymus vulgaris, Cinnamomum verum, Melissa officinalis, Nepeta cataria, Cymbopogon citratus, Mentha piperita, Melaleuca alternifolia, Eucalyptus radiata and Syzygium aromaticum on the main bacteria, responsible for infections of the upper respiratory system (S. pneumoniae, S. pyogenes, H. influenzae, M. catarrhalis $) \cdot(20,21)$

In some situations, the association with essential oils allows the reducing of the minimal efficient doses of antibiotic, and automatically the diminishing of the adverse effects of the antibiotic (18).

Due to the fact that very often, the antibiotics and the essential oils have different acting mecha- nisms, the latter may facilitate the action of the antibiotic, removing the already installed bacterial resistance. Thus, the essential oils may act:

- against the beta-lactamase production $(14,22)$;

- by inhibition of the bacterial efflux pump (22);

- by permeabilization or destructuration of the bacterial cell membrane (23);

- by anti-quorum sensing (24).

\section{Antiviral activity of the essential oils}

The main antiviral battle mechanisms identified in the aromatic oils are represented by: cytotoxic effect, inhibition of the replication cycle, alteration of the structural proteins, blocking of the receptors necessary for the intra-cellular penetration. Essential oils have been proven to be efficient in vitro against a significant amount of viruses, as well DNA, as also RNA: HSV-1, HSV-2, the flu virus, Polio V., Dengue virus type 2, Junin virus, adenovirus, Coxsackie virus B1. (25-29)

\section{Antifungal activity of the essential oils}

Hammer and colleagues show the complex mechanisms, which represent the basis of the antifungal activity of the essential oils, emphasizing: alterations of the cell membrane by enhancing its permeability, alteration and disorganization of the membrane proteins, inhibiting of the cell breathing, modifying of the transportation processes of ions, intra and extra-cellular (30). The antifungal effects were proven against: Candida Albicans, C. glabrata, Saccharomyces cervisie, Aspergillus fumigates. $(23,30-31)$

\section{CONCLUSIONS}

Created by plants for protection and defense, the essential oils have proven to possess extraordinary abilities in the fight against bacteria, fungi and viruses.

Their complex chemical composition represents a very efficient mechanism, for avoiding the installing of the microbial resistance and at the same time, diversifying the directions in the antimicrobial battle.

Associated to the therapy with antibiotics, they manifest not only a synergic effect to these, but also support the action of antibiotics, as well as their action spectrum, allowing altogether the reducing of the minimal inhibitory dosage and thus reducing the adverse effects of antibiotics. And all these, without aggressing the human body.

Although they were used by mankind for over 7,000 years, we may say that the knowledge of the 
role and the contribution of the essential oils to Medicine, as well as their recognition, are yet only at the beginning.

In the context of the nowadays crisis, generated by the alarming installing of the microbial resis- tance to the synthesis antibiotics and by the lack of perspectives for new antibiotics, we should return our interest to these natural products, of such great value.

\section{BIBLIOGRAPHY}

1. Cockburn T.A. The Evolution and Eradication of Infectious Diseases. Perspect Biol Med. 1964; 7:498-9.

2. Boire N.A. Essential Oils and Future Antibiotics: New Weapons against Emerging "Superbugs"? J Anc Dis Prev Remedies [Internet]. 2013 [cited 2014 Oct 23]; 01(02). Available from: http://www. esciencecentral.org/journals/essential-oils-and-future-antibiotics-newweapons-against-emerging-superbugs-2329-8731.1000105. php?aid $=14230$

3. Rossolini G.M., Arena F., Pecile P., Pollini S. Update on the antibiotic resistance crisis. Curr Opin Pharmacol. 2014 Sep 22; 18C:56-60

4. $\mathrm{CDC}$ - Carbapenem-resistant Enterobacteriaceae - HAI [Internet]. Available from: http://www.cdc.gov/hai/organisms/cre/

5. $\mathrm{WHO} \mid$ Antimicrobial resistance [Internet]. WHO. Available from: www. who.int/mediacentre/factsheets/fs194/en/

6. Woolhouse M., Farrar J. Policy: An intergovernmental panel on antimicrobial resistance. Nature. 2014 May 22; 509(7502):555-7.

7. Lopes-Lutz D., Alviano D.S., Alviano C.S., Kolodziejczyk P.P. Screening of chemical composition, antimicrobial and antioxidant activities of Artemisia essential oils. Phytochemistry. 2008 May; 69(8): 1732-8.

8. Istudor V. Noțiuni introductive de aromaterapie. Orientări moderne în fitoterapie şi aromaterapie. Editura Tehnoplast Bucureşti; 2013. $\mathrm{p}: 118-44$.

9. Bassolé I.H.N., Juliani H.R. Essential Oils in Combination and Their Antimicrobial Properties. Molecules. 2012 Apr 2; 17(12): 3989-4006.

10. Yap P.S.X., Yiap B.C., Ping H.C., Lim S.H.E. Essential Oils, A New Horizon in Combating Bacterial Antibiotic Resistance. Open Microbiol J. 2014; 8:6.

11. Wolska K.I., Grzes K., Kurek A. Synergy between novel antimicrobials and conventional antibiotics or bacteriocins. Pol $J$ Microbiol. 2012; 61(2):95-104.

12. Burt S. Essential oils: their antibacterial properties and potential applications in foods - a review. Int J Food Microbiol. 2004 Aug 1; 94(3):223-53.

13. Burt S.A., Reinders R.D. Antibacterial activity of selected plant essential oils against Escherichia coli 0157:H7. Lett Appl Microbiol. 2003; 36(3):162-7.

14. Si H., Hu J., Liu Z., Zeng Z. Antibacterial effect of oregano essential oil alone and in combination with antibiotics against extendedspectrum beta-lactamase-producing Escherichia coli. FEMS Immunol Med Microbiol. 2008 Jul; 53(2):190-4.

15. Van Vuuren S.F., Suliman S., Viljoen A.M. The antimicrobial activity of four commercial essential oils in combination with conventional antimicrobials. Lett Appl Microbiol. 2009 Apr;48(4):440-6.

16. Mahboubi M., Bidgoli F.G. Antistaphylococcal activity of Zataria multiflora essential oil and its synergy with vancomycin. Phytomedicine Int J Phytother Phytopharm. 2010 Jun; 17(7):548-50.

17. Guerra F.Q.S., Mendes J.M., Sousa J.P. de, Morais-Braga M.F.B., Santos B.H.C., Melo Coutinho H.D., et al. Increasing antibiotic activity against a multidrug-resistant Acinetobacter spp by essential oils of Citrus limon and Cinnamomum zeylanicum. Nat Prod Res. 2012; 26(23):2235-8.
18. Rosato A., Vitali C., De Laurentis N., Armenise D., Antonietta Milillo M. Antibacterial effect of some essential oils administered alone or in combination with Norfloxacin. Phytomedicine Int J Phytother Phytopharm. 2007 Nov; 14(11):727-32.

19. Weseler A., Geiss, H.K., Saller R., Reichling J. A novel colorimetric broth microdilution method to determine the minimum inhibitor concentration (MIC) of antibiotics and essential oils against Helicobacter pylori. Pharmazie. 2005; 60:497-502.

20. Inouye S., Yamaguchi H., Takizawa T. Screening of the antibacterial effects of a variety of essential oils on respiratory tract pathogens, using a modified dilution assay method. J Infect Chemother Off J Jpn Soc Chemother. 2001 Dec; 7(4):251-4.

21. Inouye S., Takizawa T., Yamaguchi H. Antibacterial activity of essential oils and their major constituents against respiratory tract pathogens by gaseous contact. J Antimicrob Chemother. 2001 May;47(5):565-73.

22. Lorenzi V., Muselli A., Bernardini A.F., Berti L., Pagès J.-M., Amaral L., et al. Geraniol restores antibiotic activities against multidrug-resistant isolates from gram-negative species. Antimicrob Agents Chemother. 2009 May; 53(5):2209-11.

23. Cox S.D., Mann C.M., Markham J.L., Bell H.C., Gustafson J.E., Warmington J.R., et al. The mode of antimicrobial action of the essential oil of Melaleuca alternifolia (tea tree oil). J Appl Microbiol. 2000 Jan; 88(1):170-5.

24. Szabó M.A., Varga G.Z., Hohmann J., Schelz Z., Szegedi E., Amaral L., et al. Inhibition of quorum-sensing signals by essential oils. Phytother Res PTR. 2010 May; 24(5):782-6.

25. García C.C., Talarico L., Almeida N., Colombres S., Duschatzky C., Damonte E.B. Virucidal activity of essential oils from aromatic plants of San Luis, Argentina. Phytother Res PTR. 2003 Nov; 17(9):1073-5.

26. Bourne K.Z., Bourne N., Reising S.F., Stanberry L.R. Plant products as topical microbicide candidates: assessment of in vitro and in vivo activity against herpes simplex virus type 2. Antiviral Res. 1999 Jul; 42(3):219-26.

27. Loizzo M.R., Saab A.M., Tundis R., Statti G.A., Menichini F., Lampronti I., et al. Phytochemical analysis and in vitro antiviral activities of the essential oils of seven Lebanon species. Chem Biodivers. 2008 Mar; 5(3):461-70.

28. Reichling J., Koch C., Stahl-Biskup E., Sojka C., Schnitzler P. Virucidal activity of a beta-triketone-rich essential oil of Leptospermum scoparium (manuka oil) against HSV-1 and HSV-2 in cell culture. Planta Med. 2005 Dec; 71(12):1123-7.

29. Martin K.W., Ernst E. Antiviral agents from plants and herbs: a systematic review. Antivir Ther. 2003 Apr; 8(2):77-90.

30. Hammer K.A., Carson C.F., Riley T.V. Antifungal effects of Melaleuca alternifolia (tea tree) oil and its components on Candida albicans, Candida glabrata and Saccharomyces cerevisiae. J Antimicrob Chemother. 2004 Jun; 53(6):10815.

31. Pinto E., Pina-Vaz C., Salgueiro L., Gonçalves M.J., Costa-deOliveira S., Cavaleiro C., et al. Antifungal activity of the essential oil of Thymus pulegioides on Candida, Aspergillus and dermatophyte species. J Med Microbiol. 2006 Oct; 55(Pt 10):1367-73. 